\title{
CORRIGENDUM
}

\section{Prophylaxis and treatment of GVHD: EBMT-ELN working group recommendations for a standardized practice}

T Ruutu, A Gratwohl, T de Witte, B Afanasyev, J Apperley, A Bacigalupo, F Dazzi, P Dreger, R Duarte, J Finke, L Garderet, H Greinix, E Holler, N Kröger, A Lawitschka, M Mohty, A Nagler, J Passweg, O Ringdén, G Socié, J Sierra, A Sureda, W Wiktor-Jedrzejczak, A Madrigal and D Niederwieser, a working group of the European Group for Blood and Marrow Transplantation (EBMT) and the European LeukemiaNet (ELN)

Bone Marrow Transplantation (2014) 49, 319; doi:10.1038/bmt.2013.210; published online 23 December 2013

Correction to: Bone Marrow Transplantation (2014) 49, 168-173; doi:10.1038/bmt.2013.107; published online 29 July 2013

Since the publication of this article the authors have noticed an error in Table 1 under the section Treatment of GVHD. The dose of budesonide has been given as $9 \mathrm{mg} / \mathrm{kg} / \mathrm{day}$. It should be $9 \mathrm{mg} /$ day. The corrected section appears below.

\section{Treatment of GVHD}

Treatment of acute GVHD

First-line treatment

The first-line treatment of acute GVHD is MP.

Treatment is initiated for acute GVHD of grade II or higher.

The initial MP dose is $2 \mathrm{mg} / \mathrm{kg} / \mathrm{day}$.

MP is given in two divided doses per day.

The initial dose is continued for 7 days. Treatment can be changed in case of clear progression after 5 days, but there is no evidence that change in treatment will affect the outcome.

No reduction of the dose is done during the first 7 days.

Tapering of the dose is done slowly and depending on the response. No marked dose reductions are done in the early phase. MP is not discontinued before all signs of GVHD have disappeared.
Failure of treatment (corticosteroid resistance) is defined as no response after 7 days of treatment or clear progression after 5 days.

Non-absorbable oral steroid (budesonide) is given, along with systemic corticosteroid, for GI GVHD in the dose of $9 \mathrm{mg} /$ day in one daily dose p.o.

Topical steroids are used for skin GVHD according to centre policy.

The decision to initiate treatment is based on clinical signs. Skin biopsy before initiation of treatment is recommended, but the decision to treat should not depend on the biopsy result. The same recommendation applies to upper $\mathrm{Gl}$ or sigmoid biopsy if $\mathrm{Gl}$ manifestation is suspected.

This error also occurred in the sentence below, this has now been corrected.

Non-absorbable oral steroid treatment (budesonide $9 \mathrm{mg} /$ day) is recommended along with systemic therapy in the case of gastrointestinal GVHD. Budesonide and beclomethasone are both being used for gastrointestinal GVHD; they have different pharmacological characteristics and might have different effects on upper or lower gastrointestinal tract GVHD. There are no comparative studies to date; hence budesonide is recommended in the absence of a prospective trial.

The authors would like to apologize for any inconvenience caused. 